\title{
Cohort Supervision: Towards a Sustainable Model for Distance Learning
}

\author{
Judy van Biljon ${ }^{1} \mathbb{D}$, Colin Pilkington ${ }^{2(\otimes)}\left(\mathbb{D}\right.$, and Ronell van der Merwe $^{2}$ (D) \\ 1 Department of Information Systems, University of South Africa, \\ Florida Park, Roodepoort, South Africa \\ vbiljja@unisa.ac.za \\ 2 Department of Computer Science, University of South Africa, \\ Florida Park, Roodepoort, South Africa \\ \{pilkicl, vdmerwer\}@unisa.ac.za
}

\begin{abstract}
In response to the challenge of increasing supervision capacity while at the same time also improving the supervision experience, we used a design science research approach to guide the design, implementation and evaluation of a cohort supervision model for master's students in computing at an open-distance university. This paper describes the implementation of a cohort programme in 2018, the findings from data collected during a focus group with students and supervisors, students' reflective evaluations at the end of the module, feedback from the supervisors, and our reflective notes. Our main theoretical contribution is the cohort model proposed for developing supervision capacity at master's level. Our practical contribution is a method for a practical supervision model for master's students based on the concepts of co-operative learning and conversational theory.
\end{abstract}

Keywords: Post-graduate supervision · Group supervision · Cohort supervision · Distance education $\cdot$ Design science

\section{Introduction}

Massification and marketisation of higher education have resulted in increasing numbers of research candidates with different levels of capabilities entering postgraduate studies nationally and internationally [5]. Universities are under pressure because of the growing number of students doing research and the increased emphasis on completion rates. This is particularly the case also at our University of South Africa, as its approach to open distance learning (ODL) is aimed at "bridging the time, geographical, economic, social, educational and

Supported by the South African Research Chairs Initiative of the Government's Department of Science and Technology, and the National Research Foundation of South Africa (Grant No. 98564).

(C) Springer Nature Switzerland AG 2020

B. Tait et al. (Eds.): SACLA 2019, CCIS 1136, pp. 147-162, 2020.

https://doi.org/10.1007/978-3-030-35629-3_10 
communication distance between student and institution, student and academics, student and courseware, and student and peers" [27]. In the context of little face-to-face teaching, ODL focuses on greater flexibility and removing barriers, leading to wider access to learning, greater student-centricity and support, as well as a focus on student success. Not only has this openness led to significantly increased student numbers; the realities of the South African society led to the admission of students who vary widely in their readiness for postgraduate study, with those from disadvantaged areas and schools lacking logical writing skills [13]. The increasing student numbers, in combination with students' lack of preparedness for postgraduate studies, put pressure on supervision capacity, because the increase in student numbers has not been met by a corresponding increase in the provision of experienced supervisors [3,5]. Given the risks and the impact of failed supervision, higher education institutions cannot afford to have novice supervisors follow a trial-and-error approach [22]. The need is not only to increase the number of supervisors but also to provide experiential supervision training. This discrepancy between required and available supervision capacity is the rationale for this paper in which we seek to explore the following

Research question: What are the components of an effective model for cohort supervision in distance learning which increases supervision capacity while providing support and experiential learning to supervisors of different experience levels?

The term cohort model refers to a group or unit set up as a structure in a community of learning to support intellectual development and knowledge production in postgraduate education research [11]. The use of cohort supervision to address the problem of improving supervision capacity is not new: several previous studies investigated doctoral cohort supervision [10]. Dysthe, Samara, and Westrheim proposed a three-pronged approach in master's supervision combining supervision groups, student colloquia and individual supervision [6]. More recent studies published on master's cohort supervision include [15,21]. Cohort studies focusing on both master's and doctoral supervision include [23], although not in an ODL context. Manyike investigated supervisor challenges in the supervision of master's and doctoral students in an open distance e-learning institution in South Africa [14]. She suggested collaboration between experienced and novice supervisors as means of enhancing the quality of feedback and communication but did not propose a new model. Similarly, [3] described supervisor development as part of cohort supervision in ODL and proposed a cohort supervision model at 'honours' level. ${ }^{1}$ Besides considering master's cohort supervision at an ODL institution, the contribution of this paper lies in the concomitant development of supervision capacity at different experience levels.

\footnotetext{
${ }^{1}$ For readers from outside South Africa: The 'honours' level in South Africa is a voluntary 'top-up' to a shorter Bachelor degree - somewhat comparable to the final stage of the longer Bachelor curriculum in the USA. The 'honours' level is typically a prerequisite for commencing master-studies in South Africa.
} 


\section{Related Work}

We used the pattern 'postgraduate supervision' AND ('group supervision' OR 'cohort supervision') to search the ACM, Springer, ERIC, Scopus and Web of Science databases for the years 2013-2018 (in January 2019). The total number of full-papers from each database were as follows: ACM 3484, ERIC 115, Scopus 780 , Springer 3526, and Web of Science 457. Thus the number of papers in most of the databases was too large for complete analysis. Therefore we considered only the top 20 papers (rated by relevance) of each database, i.e.: 100 papers altogether-actually 96 after some duplicates were removed. We then read their abstracts and removed 55 papers that did not relate to post-graduate supervision in our field (ICT). The remaining 41 papers came from various countriesincluding South Africa, Australia, the United Kingdom, China, the USA, the Netherlands, New Zealand, Denmark, Finland, Sweden, Japan, Israel, Colombo, Malaysia, and Mauritius - which indicates that our problem is globally relevant. The research methods used in those studies included individual interviews (14) and group interviews (3), surveys (24), focus groups (5), case studies (2), and observations (2). ${ }^{2}$ These salient publications can be summarised w.r.t. advantages, disadvantages, best practices (including cohort models proposed), and critical success factors as described below.

Cohort supervision is proposed as an alternative pedagogy for the supervision of large groups of master's students in an efficient and effective manner, maintaining quality research and graduate output [15]: this approach improved students' motivation through peer-sharing of experiences and feedback, as well as students taking responsibility for their own academic progress. Ahern (et al.) noticed enhanced morale, the benchmarking of learning and learning from others' mistakes, as well as collegiality [1]. The benefit to supervisors included the sharing of ideas, what constituted best practice, and strategies for improving supervision. Addressing capacity constraints is an important motivation for using cohort supervision $[1,2]$, though Choy (et al.) warned that universities need to invest both time and resources for cohort development if such a cohort approach is to yield good results as a supervision model [4].

Considering the challenges supervisors experienced in group supervision as part of a guidance and counselling master's programme, Wichmann-Hansen (et al.) identified three major challenges experienced by the cohort supervisors: (1) promoting equal participation within student groups that are often heterogeneous, (2) ensuring a balance between providing answers and involving students, and (3) recognising and growing students' analytical skills [28]. Meng (et al.) found that informational contextual factors promoted intrinsic motivation, whereas controlling contextual factors have negative effects [16].

Papers considering best practices for cohort supervision emphasise the importance of providing a holistic, integrated approach. For example, [24] mentions the fundamental principles of connectedness, wholeness and being. Hutchings main-

\footnotetext{
$\overline{2}$ Those methods are not mutually exclusive; one research design might use more than one of those methods.
} 
tains that group supervision can foster sustained mutual support [9] and proposes technology-mediated interactions which are not tied to a specific location-thus facilitating participation and reducing isolation. Maor and Currie support their argument for the use of technology by focusing on the transformational role that it can play in the move from more traditional, dyadic forms of supervision to more collaborative group processes [12]. Other papers specify the specific elements of best practice, like scaffolding, guiding students in the completion of key learning tasks involved in writing a dissertation proposal independently [21], or using proactive communication to engage in meaningful preparation before meetings [20]. Han and Schuurmans-Stekhoven recommend comprehensive research literacy training [7], which should include the critical search for information, understanding, interpreting and evaluating as well as finally synthesising it.

Various studies proposed alternative cohort supervision models. Choy (et al.) investigated the development of postgraduate research degrees cohorts [4]. Their approach included four provisions, namely an initial residentially based workshop, developing a learning community, cultivating scholarship, and spaces for continuing learning. Their interventions resulted in the development of a learning environment that supported students and a culture that was nurturing [4]. Marnewick and Nel proposed an efficient and effective master's programme that would lead to good quality research and improved graduate output [15]. Their findings indicate that peer feedback, sharing experiences in the group, and students taking responsibility for their own progress led to improved student motivation. The benefits of the cohort model to the supervisors included sharing of ideas and best practices, as well as shared strategies for improving supervision [15]. In some of our own research group's earlier work [3] we proposed a pyramid cohort supervision model (PCSM) for supervising computing honours students in an ODL environment. That model was based on cooperative learning, conversational theory and scaffolding, whereby the model purposefully integrated technology as part of student support and collaboration [3].

The critical success factors relating to the supervisors include the following: a supervisor's own knowledge [26], availability and willingness to help [29], work load and the pressures of the academic environment $[15,22]$, and the quality of feedback given in formal supervision meetings which require advance preparation [20]. The importance of feedback is also emphasised in [18] whereby, moreover, the harmony between (co)supervisors has an effect on the supervisor-supervisee relationship. Other skills include coaching, scaffolding and support in articulation and reflection practices [19]. Spiller (et al.) recognised further factors that may influence the success of cohort supervision: cross-cultural environments, copublishing with students, supervisor and student negotiations to ensure common understanding about important aspects, and written feedback on students' drafts [25]. Njie (et al.) argued that supervisors need to be involved in group activities to counter-act unwanted practices such as 'free riding' (not contributing to group activities) [17]. The number and diversity of the personal and contextual factors affecting cohort supervision signifies the complexity of the task and the expectation of the skills required. 
As far as the students are concerned, Marnewick and Nel mention crosscultural issues, barriers related to language differences, the lack of academic resources, unrealistic expectations by students, lack of academic scholarship in students, and the academic pressure experienced by supervisors, as important factors [15]. Also highlighted are barriers to communication with lecturers [21], which is exacerbated by students' level of language proficiency [22]. Furthermore, students' misunderstanding of the scope of postgraduate studies and their lack of critical thinking skills need to be considered [22]. Manyike investigated ODL supervision and identified weaknesses in the following areas [14]: allocating postgraduate students to supervisors without consultation, meeting the needs of students who come to postgraduate studies underprepared by guiding them during the thesis-writing process, as well as the challenges inherent in an ODL model which relies primarily on written communication. Co-supervision as part of cohort supervision was highlighted as more than just a 'safety net' for institutions [18]; it leads to a complex web of both interpersonal and institutional relationships (which carry power) whilst also providing opportunities (as there are many ways in which co-supervision can be organised). Therefore it minimises the risk of dual relationships and increased supervisors' opportunity to experience both leading and participating in groups [4].

In summary, the papers recapitulated above support the argument that cohort supervision has potential for increasing supervision capacity and quality, and that the benefits extend to both students and supervisors. However, research also provides evidence of numerous and diverse problems relating to supervisors, students and their interaction. Complexity leads to the development and implementation of various context-specific cohort supervision models. To our best knowledge (to date), the only approach that specifically addresses the issue of supporting novice supervisors while developing supervision capacity in ODL is the pyramid cohort supervision approach for supervising computing honours students [3]. Therefore, we used this model as our point of departure in the research design discussed in the following section.

\section{Research Design}

For this paper we applied the well-known design science method [8]. Our research was guided by a pragmatic philosophy with a single-case study [30], whereby the units of analysis are the students. The supervisors (as collectives with the students) are our data collection sources. ${ }^{3}$ A focus group and reflective questionnaires were used as methods to gather data. The design of the intervention is based on the above-mentioned pyramid cohort supervision model [3], where a design science approach was used together with principles of constructivist learning as an active, social, meaning-making process based on individual and shared experiences [25]. Cooperative learning was also involved in assuming a positive interdependence between students in the cohort while maintaining their individual accountability [13].

\footnotetext{
${ }^{3}$ Permission was obtained from the relevant authorities at our university.
} 
Table 1. Events and actions undertaken in the cohort supervision process

\begin{tabular}{l|l|l}
\hline Stage & Event & Actions \\
\hline 1. & $\begin{array}{l}\text { Introduction and } \\
\text { orientation }\end{array}$ & $\begin{array}{l}\text { Providing a tutorial letter detailing the purpose of } \\
\text { the proposal module, tasks, deadlines, resources } \\
\text { and organizational support. Providing online } \\
\text { resources (including literature) in a wiki }\end{array}$ \\
\cline { 2 - 3 } & 1st meeting: (March) & $\begin{array}{l}\text { Group meeting between students, supervisors, } \\
\text { administrative support staff, and practitioners, for } \\
\text { feedback on initial research questions }\end{array}$ \\
\hline 2. & $\begin{array}{l}\text { Research } \\
\text { questions/design }\end{array}$ & $\begin{array}{l}\text { Individual meetings with supervisors, informal } \\
\text { group interaction }\end{array}$ \\
\cline { 2 - 3 } & 2nd meeting: (May) & $\begin{array}{l}\text { Presentations to group and external supervisor on } \\
\text { literature review, research questions, research } \\
\text { design }\end{array}$ \\
\hline 3. & 3rd meeting: (August) & $\begin{array}{l}\text { Proposal presentations and focus group to evaluate } \\
\text { the students' research approaches. (Our reflective } \\
\text { questionnaire was distributed only in December, } \\
\text { after all assessment marks had been finalised) }\end{array}$ \\
\hline
\end{tabular}

For this paper, however, our approach is different in the following ways. We now apply the model to the proposal development phase for master's students in computing, thus hoping to use collaborative peer approaches to encourage the students to critique each other's work, and - in so doing-learn how to critique their own work, too. Thus we hope to yield more solid proposals. As far as support is concerned, we enlisted the help of a part-time administrator for organising the interactions and the reporting, and we also involved external domain experts and experienced supervisors as far as necessary (and available). In our practice we introduced face-to-face meetings for student presentations and feedback. ${ }^{4}$

The specific interventions are listed in Table 1. Our cohort consisted of seven students (master's students who registered for the 'research proposal' module in 2018 with a senior supervisor) and three supervisors (of varying levels of supervision experience). The central idea was to support the postgraduate students in the preparation of their proposals by bringing together a cohort of students who would be working in similar fields, so that they can learn from each other. ${ }^{5}$ A project site was created on the web-based learning management system that included (amongst others) tutorial letters, background information to the proposal module, as well as links to important resources. Some initial training was offered in the form of a workshop as well as in providing an opportunity for the students to discuss their research topics and questions. This discussion took

\footnotetext{
${ }^{4}$ In 'pure' distance education without seminar rooms, technical means like 'Skype' can be used to facilitate 'virtual meetings' via the Internet.

${ }^{5}$ For comparison see the 'post-graduate school' models in various implementations in different countries.
} 
place in small groups of students as they considered each other's work, as well as between individual students and one of the supervisors.

A subsequent group event provided students with the opportunity to present their work, to develop skills in condensing their ideas into presentation format (introduction, research questions, brief literature review, and proposed methodology) and to present them in spoken words. The students were also expected to critique another student's work and to give constructive feedback, thereby commenting on strengths, weaknesses, and gaps in the other student's argument. Meta feedback was provided by peers, supervisors, and external supervisors who were brought in to add objectivity and new perspectives; this was achieved in a large group with all participants present. A third group meeting was held in which the students again had to present an outline of their proposal to the group and to receive feedback from supervisors and peers. This again took place as a whole-group event.

In the time between these group events, the students submitted drafts of their work to the supervisors for feedback. Students were initially allocated two supervisors, which was however not done in a 'classical' primary/co-supervisor arrangement: instead, the senior supervisor in the supervisory group was involved in all participating students' work.

\section{Results}

\subsection{Evaluation Based on the Students' Responses}

Reflective Survey. The students were asked to complete a reflective questionnaire focused on their experience of the cohort supervision; our reflective questions are provided in Appendix A. The following discussion is a summary of the insights gained from a thematic analysis of the responses. Our findings are structured w.r.t. benefits and drawbacks of cohort supervision as experienced by the students in the group, as well as the critical success factors (requirements to make the approach useful) and recommendations towards improving the model. The different respondents are represented by capital letters in square brackets.

Considering benefits, all students noted benefits associated with the cohort supervision process. It provided an overview, allowing students "to know where everyone is in their studies and not to miss deadlines! It kept me on track" $[F]$. The collective nature was noted in the team work "from both colleagues and the supervisor" $[B]$, which afforded the students the possibility of tapping into "collective intelligence for problem solving" $[A]$. Another student noted: "Comments from various persons helped me in writing the proposal" $[E]$. The same student also obtained advice "on what needed to be improved" $[E]$, whereby awareness was raised "on some aspects of the proposal that were not clear" $[E]$. Furthermore, the approach helped to "build my confidence by knowing we are all learning and there are no stupid questions" $[B]$. The requirement for the students to give presentations "was very useful" $[D]$ and "improved communication and presentation skills" $[C]$. Also, the students learnt "indirectly from other students because you see how they do things during their presentations" $[D]$. 
Considering the group interactions, the cohort led to a sense of "belonging and knowing that you are not alone" [A]. Additionally, "our group has a WhatsApp group, and that is great" $[F]$, (i.e.: peer-group initiatives to enhance communication). Students gained from others in the group. "They helped a lot by sharing the articles and research papers which they thought they can benefit my research" $[C]$. They also contributing to the group: "I helped them on technical issues such as using referencing tools and explaining what is expected in each section of the proposal" $[A]$.

The extent to which the cohort process affected the quality of the work produced varied. It had its value in highlighting "what is needed in the research, starting from research topic, problem, methodologies, and literature reviews" $[C]$. However, "we could still be possibly stuck in our silo mentality when approaching our work", as "there was not much robust discussion on the WhatsApp group" $[A]$. Student $[F]$ responded: "Not really". Students also noted drawbacks from participating in cohort supervision. One student mentioned "limited time given to a student" $[A]$ to do a presentation due to the size of the group, and suggested workshops to be held more frequently. Too little contact was noted by another student: "the workshops are too little"; it would be better to "perhaps have one every second month" $[G]$. One student had not learned anything from the other students, while the other six students stated that they had learnt much from fellow students. This may be because the particular one student had started later in the year and also had a distinctly different project topic.

Success factors often focussed on contact opportunities: "Regular meetings encourage members to engage and exchange knowledge, give sufficient time to each student within a group" $[A]$. Also $[G]$ wrote: "Regular contact with students". The role of the supervisor was also mentioned: "Commitment. The lecturer was there for us and responded to emails on time" [B]. Student $[E]$ mentioned: "Evaluation, comment or feedback from all the supervisors from that group". However, the cohort approach by itself was not deemed sufficient: "one-on-one sessions with my supervisors are an absolute must. That is where I grew and learnt the most" $[F]$. "I would like a mixed approach, as group- and one-on-one sessions are all important" $[A]$.

Focus Group. A focus group discussion was held with our students to gauge their collective view of the approach that had been taken to their supervision. Five main themes emerged from a thematic analysis of the focus group transcription.

Students commented on their initial expectations of the supervision process. Apart from not being sure how it works, they had expected supervision to be based on emails and supervisor meetings. There was the expectation of meeting the supervisor maybe once or twice a month, initiated by both the student and supervisor, "because if supervisors do not do that, students can sit back and discussions between supervisor and student end up not happening". Largely, the students' expectation was that they would communicate with their supervisors via email, and that supervisors would send out messages via the university's 
LMS, whereby "if you miss something it is your fault". One-on-one meetings with supervisors were liked "because you get instant feedback and follow-on questions".

As far as the group approach is concerned, the students were "comfortable with the environment created and the support given", whereby they "learnt a lot from the workshops" and also "from each other". Thereby the students also had to learn "not to react negatively to criticism". Knowing what had been covered in the group meetings encouraged one student to realise that "I am not a quitter; I will try to make success out of this". However, it was clear that "it is not possible for me to take leave days frequently", and that group meetings should be "after working hours, it will give us an opportunity to attend". ${ }^{6}$

It is noteworthy that the students set up a WhatsApp group by and for themselves. As "everyone has a phone on-the-go, it is convenient", and "if someone has a question, it is asked and anyone can answer". This tool "created unity amongst the students", as well as it built "a sense of comfort", because otherwise "this journey can be a lonely journey". There was an appreciation of the group and a belief that the students benefited from belonging to it. Nonetheless, the students "have not really shared each other's papers", and did also not appear to "share and ask the difficult questions".

As far as the future of the group is concerned, there was a feeling that they enjoyed this method, that it would be good to continue working in this manner, and that the group should not be split along any topic area lines. The group also expressed the belief that its members would be able to advise future proposal students about what is expected in this module.

As the students were expected to present their research topics, presentation skills was identified as yet another theme in the focus group discussion. The students took their presentations "very seriously", and prepared themselves by "watching YouTube videos", by checking "the dos and don'ts and expectations", as well as by asking "experienced friends".

\subsection{Evaluation Based on the Supervisors' Responses}

As part of the reflective process, the supervisors completed a questionnaire about their experiences of cohort supervision; the questions are listed in Appendix B.

W.r.t. the question of whether the cohort supervision approach met the expectations of the individual supervisors, the respondents reflected that the cohort supervision model provides a platform for "quality assurance on many levels, including supervision practices, disciplinary content and general research knowledge". One respondent indicated that the cohort process addressed some of the anxieties experienced by novice supervisors. This was also emphasised by another respondent who indicated that the process provides " a safety net against individual biases, inexperience and ignorance for both students and supervisors" on various levels, including the management of individual experiences, personality clashes, and overall administration problems. Reflecting on the organisational processes, all respondents mentioned that they did not realise the extent of the

\footnotetext{
${ }^{6}$ Many of our students are employed in day-time jobs.
} 
complexity of the organisational overheads, and that it would not have been possible to do this without the administrative assistant. One respondent mentioned that, because the projects were all different, it made reading and conceptualising the different projects difficult. The more senior supervisor also commented on the mentor-mentee process and the danger that lies in this process of supervising not only the students but also the less experienced supervisors. One of the less experienced respondents mentioned that more defined rules for both the supervisors and the students should have been set before the project.

The supervisors agreed that the students benefited from the cohort supervision as it assisted the students with peer support on "emotional, cognitive and organisational" levels. From conversations with the students it was learned that the students created their own support group, separate from the official cohort group. One respondent mentioned the positive input that has been received from several sources: the advice provided by the external expert supervisors during the initial group sessions, the positive feedback students who attended a postgraduate workshop at a local conference received, as well as the assistance of, and advice from, a post-doctoral fellow. Moreover, the respondents agreed that the approach positively affected the completion rate for the students. One respondent mentioned that, compared to previous years, the students received more input and that the proposals were of a better quality as a result.

In reflecting on what the supervisors would change, the respondents identified that the field of research should be better defined, and that students should be linked to a specific supervisor earlier in the process. This would eliminate the problem of a student redundantly contacting multiple supervisors. The "lack of a shared platform" also resulted in too many emails being sent. One respondent commented on teaching the students the skills required to critique their peers' work. Another one suggested the introduction of a structured presentation template that would support students in presenting (and thus getting feedback on) the critical details of their research design, rather than dwelling on interesting but irrelevant details regarding the rationale for their projects.

\section{Discussion and Recommendations}

\subsection{Discussion of the Results}

It is possible to understand the results w.r.t. shared experience, a concept that emerged from our literature review. This shared experience added value for both students and supervisors.

The shared journey was for our students an opportunity to see that they were not alone and that they belonged to a group that, together, learnt what was required in a research proposal. The WhatsApp group that they created points to their initiative in supporting each other, if only from a social and administrative standpoint. This built confidence. Another insight was the importance of presentation opportunities were students could get instant and balanced feedback, and could learn together how to present their work in the most efficient manner. 
However, the students will not necessarily have learnt from others in all situations, and the need for regular as well as one-to-one meetings was highlighted. It could be argued that a mixed approach that merges cohort and individual supervision is most likely to meet most academic and social needs.

A shared approach which included external expertise also had benefits for the supervisors - albeit more for the junior supervisors with less experience than the more experienced ones. This support was noticeable in the 'backup' that colleagues offered to early-career supervisors, and in ensuring that quality did not rest on an individual's shoulders alone. The shared experience entailed a shared responsibility.

However, two further points must be noted. Firstly, a cohort supervision model does not save supervision time, and in fact increases the work that a supervisor has to do (as each piece of work is now read by two supervisors instead of one). It is thus unlikely to solve immediate supervision capacity problems. However, this extra effort may be considered as an 'investment' in future supervision capacity if we consider the experience that is gained by junior supervisors in the process which may lead to better sole supervision later. Secondly, the expectation that the students analyse each other's work, and provide constructive feedback which helps them to critically analyse their own work, was somewhat too naive. The comments provided tended to be superficially positive, such that it will be necessary to focus on training students in what to look for when reviewing and analysing academic work in future iterations of our approach. Our findings confirm the value of student colloquia for personal support. They serve as a first filter for ideas and texts, and also bring to light any needs for individual supervision sessions for more specific advice [6]. In our investigation, the supervision groups only started to form towards the end of the first year; perhaps smaller groups would form a better forum for the critical multi-voiced feedback that we found lacking.

\subsection{Proposed Cohort Supervision Model}

The proposed components of our model for cohort supervision, which is based on the experience described above, are shown in Fig. 1. The components consist of the actors and the relationships between them as well as the recommended resources. The actors include the cohort leader, supervisors, the administrator, external experts, and the students. A cohort leader must be an experienced supervisor who can lead a project and can provide 'vision' and guidance where necessary. This person may or may not serve as immediate supervisor to the students. The supervisors are supported by two further role-players: an administrator, who assists in managing the flow of documents and in organising the cohort meetings, and the external experts, who join the cohort on suitable occasions to provide domain knowledge, expert advice, and alternative viewpoints. The students thus benefit from a well-managed process, appropriate supervision, and expert input.

Several resources may be utilised. Shared resources are used to benefit the whole cohort and the process of cohort supervision. Academic resources are 


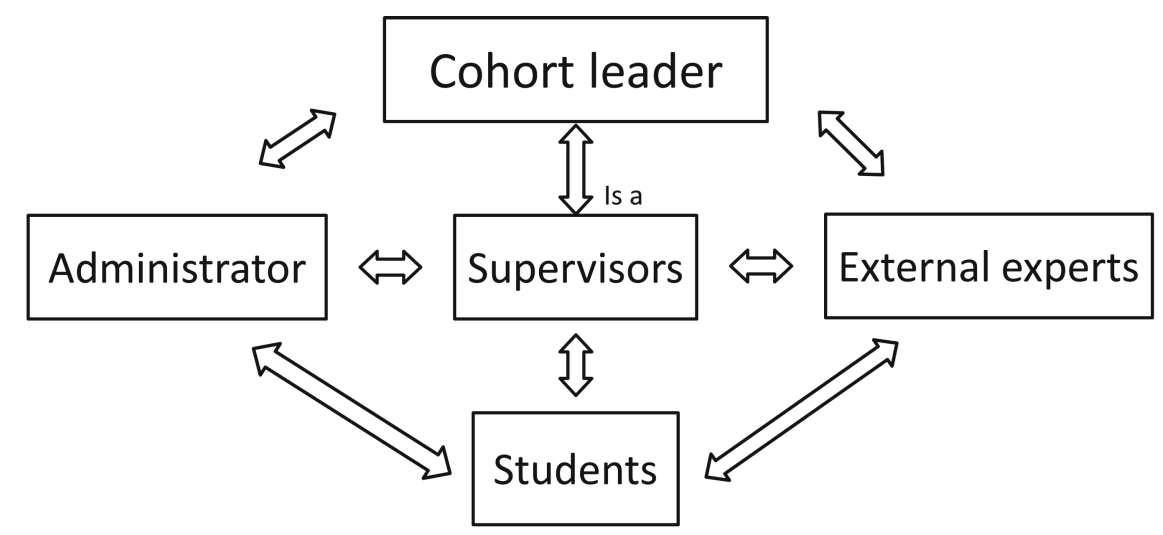

\begin{tabular}{|c|c|c|c|}
\hline Shared resources & Academic resources & Cooperative resources & Evaluation resources \\
\hline $\begin{array}{ll}\text { - } & \text { Domain } \\
\text { knowledge } \\
\text { - } \\
\text { Experience } \\
\text { - } \text { Administrative } \\
\text { support }\end{array}$ & $\begin{array}{l}\text { - Research literature } \\
\text { - Theoretical lenses } \\
\text { - Research design } \\
\text { - Presentation skills } \\
\text { Academic writing } \\
\text { skills }\end{array}$ & $\begin{array}{l}\text { - Workshops } \\
\text { - Meetings } \\
\text { - Presentations } \\
\text { - Digital resources }\end{array}$ & $\begin{array}{ll}\text { - } & \text { Formative } \\
\text { evaluations } \\
\text { - Summative } \\
\text { evaluations } \\
\text { - Verbal feedback } \\
\text { - Formal written } \\
\text { feedback/rubrics }\end{array}$ \\
\hline
\end{tabular}

Fig. 1. Proposed cohort supervision model

those that support proposal content development (reading/writing). Cooperative resources are 'places' where all role players in the process get together to further the supervision process. Evaluation resources encompass the processes w.r.t. giving feedback.

\subsection{Recommendations}

Our findings confirm the benefits of cohort supervision in developing capacity and providing emotional, intellectual and practical support for students and supervisors. Our most important contribution lies in uncovering new challenges related to cohort supervision and in suggesting recommendations to address some of these problems.

Institutional. Institutional practices need to support co-supervision explicitly by providing administrative support, since cohort supervision creates an organisational overhead. Such a support person shall manage the flow of documents, organise cohort meetings, handle queries around registration, bursary applications, ethical research clearance permissions, and the like.

Furthermore, the interactions between the cohort supervisors and the students need to be managed for sustainability. The load on the cohort supervisor can become insurmountable if the cohort supervisor tries to be involved with every student as well as with mentoring the cohort supervisors. If a cohort 
supervisor takes on a mentoring role with responsibility for students without being a co-supervisor, then such a cohort supervisor should be recognised as a (meta) supervisor of supervisors in order to facilitate satisfactory progress overall. Institutions need to consider introducing such a role formally in the supervision process. Currently, most higher education institutions have a postgraduate supervision model of sharing credits equally between supervisors and awarding credits per registered student supervised. Mentoring novice supervisors is purported to be important; however if mentoring is not part of the institutional rewards system, experienced supervisors may shy away from the considerable effort and responsibility the role entails.

Structural. The cohort supervision model should clearly delineate the responsibilities to preserve supervision capacity. For example, when two supervisors read the same document for providing feedback, some agreement as to whether this will be done in parallel or sequentially needs to be in place. Also the relative roles of primary and co-supervisors must be defined. Furthermore, while external experts could play a bigger part in helping students to formulate their final research questions and design decisions, how this is to be achieved needs to be negotiated with both students and supervisors, because this process may require extra time to be carried out with integrity.

Organisational. The initial face-to-face meeting, where students can get to know each other and form trust networks with their own social connections, is critical to establishing an informal social support network. Additionally, such meetings provide opportunities for students to do presentations - although the possibility of 'virtual meetings' (online) should be further explored.

Academic. The students' research topics should have sufficiently large overlaps in their 'theoretical lenses' and research methodologies. This promotes peer support since the participating students are thus more familiar with the domain and hence better able to constructively critique each other's work. External experts (and even co-supervisors) can fill gaps when students venture into areas outside the core competency areas of the cohort supervisors, but diverse topics have an efficiency trade-off. The external experts also have a quality assurance role at the proposal acceptance stage.

\section{Conclusion and Outlook to Future Work}

This paper describes the use of cohort supervision as a way to improve supervision capacity while supporting both students' research-learning and novice supervisors. Specifically, our findings concerning the implementation of a cohort supervision programme for master's student at an ODL institution highlight the benefits of our approach for students on emotional, social, cognitive, organisational and quality assurance levels. Nonetheless, institutional buy-in and administrative support will be needed to enable the sustainability of our cohort model. Besides the components proposed for an effective cohort supervision model that incorporates co-operative learning, conversational theory and scaffolding, our 
paper also contributes a method for implementing cohort supervision on master's level in an ODL context. As many students at residential universities face timeaccess- and isolation-constraints, too, our model should be applicable beyond ODL institutions as well. According to the design science approach our proposed supervision cohort model will be applied, evaluated, and reflected on in future research. Future work should consider a longitudinal study to investigate the sustainability of our approach for growing research capacity while also providing satisfactory supervision at the same time. In particular, structural interaction innovations towards improving supervision capacity deserve more attention. Additionally, whereas a qualitative study was conducted here, a more quantitative evaluation (considering, for example, student's pass rates, marks obtained, publications yielded from students' projects, and the like) may provide results that may lead to further refinement of the components of our cohort model.

Acknowledgements. Thanks to Sewisha Lehong and Donald Mothisi for advice and assistance in analysing our data. Thanks also to the audience at SACLA'2019 for interesting remarks relating to the incorporation of external sources to broaden and strengthen our cohort supervision model.

\section{A Students' Reflective Questionnnaire}

Supervision for your studies has taken place in a group setting with other students who are on the same journey. Please think about how this process has played itself out and how it has influenced your postgraduate studies, then answer the questions below giving as much detail as you can and are comfortable giving. Please note that you should feel free to be completely honest when answering these questions and none of your answers will determine your research progress in any way. Remember that these questions have no right or wrong answers.

1. Name / Gender / Age

2. When did you first register for your postgraduate studies?

3. What is the current status of your postgraduate studies?

4. Have your postgraduate studies this year been a positive or negative experience for you? Why do you say so?

5. To what extent has the group approach influenced your experience?

6. What has worked, or not worked, for you in this group process? What have been the benefits and drawbacks?

7. To what extent have the other students in the group helped you?

8. To what extent have you helped other students in the group?

9. To what extent do you believe this approach has affected the quality of your work?

10. What do you think are the critical factors for success with group supervision approaches?

11. What would you change about the group approach to supervision used?

12. This was a formal approach to group supervision where you were expected to attend and participate. How would you feel about a more informal peer support approach based on social media (or some other approach)? Would it be more appealing?

13. Would you prefer to continue in this mode of supervision or not, and why? 


\section{B Supervisors' Reflective Questionnaire}

1. What has been your experience of a group supervision approach?

(a) Has it been good or bad?

(b) To what extent is it what you expected?

2. From your observations, have the students benefited from the experience or not?

3. Identify challenges and risks in the use of such an approach.

4. How has this approach affected the quality of work submitted?

5. How has this approach affected the completion rates of students?

6. What would you change?

\section{References}

1. Ahern, C.M., van de Mortel, T.F., Silberberg, P.L., Barling, J.A., Pit, S.W.: Vertically integrated shared learning models in general practice: a qualitative study. BMC Fam. Pract. 14(144), 1-11 (2013)

2. Anderson, M., et al.: The construction of a postgraduate student and supervisor support framework: using stakeholder voices to promote effective postgraduate teaching and learning practice. J. Univ. Teach. Learn. Pract. 15(2), 6 (2018)

3. van Biljon, J.A., van Dyk, T., Naidoo, L.: Towards increasing supervision capacity: the pyramid cohort supervision model. In: Proceedings of SACLA 2014 Annual Conference of the Southern African Computer Lecturers' Association, pp. 166-173 (2014)

4. Choy, S., Delahaye, B.L., Saggers, B.: Developing learning cohorts for postgraduate research degrees. Aust. Educ. Res. 42(1), 19-34 (2015)

5. Cloete, N., Mouton, J., Sheppard, C.: Doctoral Education in South Africa: Policy, Discourse and Data. Somerset West: African Minds (2015)

6. Dysthe, O., Samara, A., Westrheim, K.: Multivoiced supervision of master's students: a case study of alternative supervision practices in higher education. Stud. High. Educ. 31(3), 299-318 (2006)

7. Han, J., Schuurmans-Stekhoven, J.: Enhancement of higher degree candidates' research literacy: a pilot study of international students. Asia Pac. Educ. Res. 26(1/2), 31-41 (2017)

8. Hevner, A.R., March, S.T., Park, J., Ram, S.: Design science in information systems research. MIS Q. 28(1), 75-105 (2004)

9. Hutchings, M.: Improving doctoral support through group supervision: analysing face-to-face and technology-mediated strategies for nurturing and sustaining scholarship. Stud. High. Educ. 42(3), 533-550 (2017)

10. Kobayashi, S., Grout, B.W., Rump, C.Ø.: Opportunities to learn scientific thinking in joint doctoral supervision. Innov. Educ. Teach. Int. 52(1), 41-51 (2015)

11. de Lange, N., Pillay, G., Chikoko, V.: Doctoral learning: a case for a cohort model of supervision and support. South Afric. J. Educ. 31(1), 15-30 (2017)

12. Maor, D., Currie, J.K.: The use of technology in postgraduate supervision pedagogy in two Australian universities. Int. J. Educ. Tech. High. Educ. 14(1), 1-15 (2017)

13. McFarlane, J.: Group supervision: an appropriate way to guide postgraduate students? Acta Acad. 42(4), 148-170 (2010)

14. Manyike, T.V.: Postgraduate supervision at an open distance e-Learning institution in South Africa. South Afric. J. Educ. 37(2), 1-11 (2017) 
15. Marnewick, A., Nel, H.: A model for postgraduate supervision of large student numbers in engineering management at the University of Johannesburg. In: Proceedings of IEEE Technology \& Engineering Management Conference, TEMSCON, pp. 394-399 (2017)

16. Meng, Y., Tan, J., Li, J.: Abusive supervision by academic supervisors and postgraduate research students' creativity: the mediating role of leader-mmember exchange and intrinsic motivation. Int. J. Leadersh. Educ. 20(5), 605-617 (2017)

17. Njie, B., Asimiran, S., Basri, R.: An exploratory study of the free-riding debacle in a Malaysian university: students' perspectives. Asia Pac. Educ. Res. 22(3), 257-262 (2013)

18. Olmos-López, P., Sunderland, J.: Doctoral supervisors' and supervisees' responses to co-supervision. J. Furth. High. Educ. 41(6), 727-740 (2017)

19. Olmos-Vega, F., Dolmans, D., Donkers, J., Stalmeijer, R.E.: Understanding how residents' preferences for supervisory methods change throughout residency training: a mixed-methods study. BMC Med. Educ. 15(177), 1-8 (2015)

20. Patel, P.: An evaluation of the current patterns and practices of educational supervision in postgraduate medical education in the UK. Perspect. Med. Educ. 5(4), 205-214 (2016)

21. Pringle Barnes, G., Cheng, M.: Working independently on the dissertation proposal: experiences of international master's students. J. Furth. High. Educ. 43(8), 1120-1132 (2019). https://doi.org/10.1080/0309877X.2018.1450965

22. Roets, L., Botha, D., van Vuuren, L.: The research supervisor's expertise or postgraduate student preparedness: which is the real concern? Afric. J. Nurs. Midwifery 19(2), 1-10 (2017)

23. Sidhu, G.K., Kaur, S., Chan, Y.F., Lee, L.F.: Establishing a holistic approach for postgraduate supervision. In: Tang, S.F., Logonnathan, L. (eds.) Taylor's 7th Teaching and Learning Conference 2014 Proceedings, pp. 529-545. Springer, Singapore (2015). https://doi.org/10.1007/978-981-287-399-6_48

24. Sidhu, G.K., Kaur, S., Choo, L.P., Fook, C.Y.: Developing a framework for postgraduate supervision. In: Teh, G.B., Choy, S.C. (eds.) Empowering 21st Century Learners Through Holistic and Enterprising Learning, pp. 255-267. Springer, Singapore (2017). https://doi.org/10.1007/978-981-10-4241-6_26

25. Spiller, D., Byrnes, G., Fergusan, P.B.: Enhancing postgraduate supervision through a process of conversational inquiry. High. Educ. Res. Dev. 32(5), 833845 (2013)

26. Stephens, S.: The supervised as the supervisor. Educ. + Train. 56(6), 537-550 (2014)

27. University of South Africa: Open Distance eLearning Policy. Pretoria (2018)

28. Wichmann-Hansen, G., Thomsen, R., Nordentoft, H.M.: Challenges in collective academic supervision: supervisors' experiences from a master programme in guidance and counselling. High. Educ. 70(1), 19-33 (2015)

29. van Wyk, N.C., Coetzee, I.M., Havenga, Y., Heyns, T.: Appreciation of the research supervisory relationship by postgraduate nursing students. Int. Nurs. Rev. 63(1), 26-32 (2016)

30. Yin, R.K.: Case Study Research: Design and Methods. SAGE, Thousand Oaks (2014) 